\title{
Yöneticilerin Demokratik-Katılımcı Yönetim Tarzlarının Çalışanların İç Girişimcilik Eğilimlerine Etkisi
}

Öz

Araştırmanın amacı, demokratik-katılımcı yönetim tarzının çalışanların iç girişsimcilik eğilimleri üzerindeki etkisini araştırmaktır. Havacılık sektöründe çalışan 136 çalışanın katılımıyla anket yapılmıştır. Anket verileri çoklu regresyon analizi kullanılarak analiz edilmiştir. İç girişimcilik ölçeğinin ve demokratik-katılımcı yönetim tarzı ölçeğinin güvenilirlikleri yüksek bulunmuştur (Cronbach's alpha $=.915$ ve .942). Regresyon analizinin sonuçlarına göre demokratik-katıllmocı yönetim tarzının iç girişimciliğin proaktiflik boyutu üzerinde istatistiksel olarak anlaml, pozitif ve yüksek düzeyde etkisi bulunmaktadır $(p<.001)$. Özerklik ve risk alma boyutları üzerinde anlamlı bir etki bulunmamaktadır.

Anahtar Kelimeler: İç giriş̧imcilik, demokratik-katılımcı yönetim tarzı, havacıllk sektörü.

\section{The Impact of the Democratic-Participative Management Style of Managers on the Intrapreneurship Tendencies of Employees}

\begin{abstract}
The aim of the research is to explore the influence of democratic-participative management style on the intrapreneurship tendencies of employees. A survey is conducted with 136 employees working in the aviation sector. Survey data are analysed using multiple regression analysis. The reliability of the intrapreneurship scale and democratic-participative management style scale is found to be high (Cronbach's alpha $=.915$ and .942). According to the results of the regression analysis, the democraticparticipative management style has a statistically significant, positive and high-level effect on the proactiveness dimension of intrapreneurship $(p<.001)$. There is no significant effect on autonomy and risk taking dimensions.
\end{abstract}

Keywords: Intrapreunership, democratic-participative management style, aviation sector.

\footnotetext{
* Dr. Öğr. Üyesi, Beykent Üniversitesi, İİBF, İşletme Bölümü, pelinsahin@beykent.edu.tr ORCID: 0000-0003-4494-3572
} 


\section{Giriş}

Girişimcilik emek, sermaye ve topraktan oluşan üretim faktörlerini bir araya getirmek faaliyetleri olarak tanımlansa da; günümüzde işletmelerin rekabet edebilmek, büyümek ve sürdürülebilir olmak için gerekli faaliyetleri de kapsamaktadır. Dolayısıyla girişimcilik hem bir işletme kurmak hem de mevcut işletmelerde değişim, yenilik, inovasyon ve yaratıcı faaliyetlerde bulunmaktır. $\mathrm{Bu}$ bağlamda girişimcilik düşünce, tutum ve davranış olarak örgütlerdeki çalışanlara öğretilmeli ve aktarılmalı; yani iç girişimcilik teşvik edilmeli ve böylece örgütsel değişim sağlanmalıdır.

Örgütsel değişimi gerekli kılan hatta belki de zorunlu kılan sebeplerin başında örgütlerin iç ve dış çevrelerindeki değişim gelmektedir. Bu sebeple işletmelerin devamlılığı ve hayatta kalabilmesi için örgütler "sürekli yenilik" felsefesini içselleştirip diri tutmalılardır. Bunu sağlayabilmek için bireylere daha fazla otonomi ve özgür düşünce imkânı sağlayan iç girişimcilik olgusu önem kazanmaktadır. Kurum içi girişimcilik olarak da ifade edilen iç girişimcilik kavramının öneminin artma sebebini Kuratko ve Hodgetts (2001: 51) örgütlerin yönetici ve çalışanlarının inovatif kabiliyetlerini kullanmalarına izin vermesi olarak ifade etmektedirler.

Günümüzde işletmelerin iç girişimciliğin farkına daha fazla varmasıyla birlikte iç girişimcilik olgusunun anlam ve önemi de artmaktadır. Bu araştırmada çalışanların iç girişimcilik eğilimlerine etkisi olabileceği düşünülen demokratik-katılımcı yönetim tarzı ile ilişsisi incelenmektedir.

\section{Literatür ve Teorik Çerçeve}

Girişimci; riski göze alarak mal veya hizmet üretmek üzere sermayenin yatırıma dönüştürülmesidir (Esposito, 2006; Hisrich vd., 2005).

İç girişimcilik (intrapreneurship) ise en kısa tanımıyla faal örgütlerdeki girişimciliktir (Ağca ve Kurt, 2007). İç girişimci de Pinchot (1985: 15) tarafından "iş fikrini uygulama sorumluluğunu örgüt içinde üstlenen kişi”" olarak ifade edilmektedir. Daha güncel bir başka tanıma göre yenilik faaliyetleri ve yönelimlerinin sürdürülmesidir (Antoncic ve Hisrich, 2001: 498). Naktiyok (2004: 64) iç girişimcinin sürecin merkezinde konumlandığını ve iş fikrini veya bir hayali kazançlı bir ekonomik gerçekliğe çevirmeye çalıştığını ifade etmektedir.

İç girişimcilik ile ilgili birçok araştırmacı farklı tanımlamalar yapmıştır. Zahra (1991) ile Sharma ve Chrisman (1999) iç girişimciliği mevcut örgütlerde yeni ürünler, işler ve özerk/yarı özerk işletmeler oluşturma olarak tanımlamaktadır. Covin ve Slevin (1991), Zahra (1993) ve Knight (1997) ise iç girişimciliği yeni ürün, hizmet, süreç, teknoloji ve metot geliştirme olarak ifade etmektedir. Daha güncel bir başka tanıma göre iç girişimcilik bir fikri başarmak üzere sergilenen bağımsızlıktır (Culhane, 2003; akt. Gürel).

İç girişimcilik ile ilgili literatür incelendiğinde üç ana başlık göze çarpmaktadır. Bunlardan birincisi iç girişimci bireyler (Pinchot, 1985); ikincisi iç girişimcilerin fonksiyonları (Jones ve Butler, 1992); üçüncüsü ise yönetimsel strateji olarak iç girişimciliktir (Rule ve Irwen, 1988; Guth ve Ginsberg, 1990; akt. Antoncic ve Hisrich, 2003: 7).

Örgüt içi girişimcilik yaklaşımları da üç sınıfta toplanmıştır. İlk yaklaşım Covin ve Slevin (1986) ile Knight (1997) tarafından savunulan girişimcilik yönelimi yaklaşımıdır. İkinci yaklaşım Zahra'nın (1993) savunduğu kurumsal girişimcilik yaklaşımıdır. Antoncic ve Hisrich'in (2003) savunduğu girişimci davranış yaklaşımı ise üçüncü yaklaşımdır. 
İç girişimcilik olgusu her işletmede aynı düzeyde olmasa da tüm örgütlerde az veya çok bulunmaktadır. Temel sorun iç girişimciliğin ne düzeyde olduğunun belirlenebilmesi, dolayısıyla ölçülebilmesi sorunudur. Bu sorunun çözümlenmesinde iç girişimcilik eğiliminin boyutları yardımcı olmaktadır. İç girişimcilik düzeyini belirleyen davranışları açıklamaya çalışan araştırmalara bakıldığında iki temel model göze çarpmaktadır. Bu modellerden ilki girişimcilik eğilimidir (Miller ve Friesen, 1983; Covin ve Slevin, 1991; Knight, 1997). Araştırmacılar girişimcilik eğilimi boyutlarını yenilik, risk alma ve proaktif davranma olarak tanımlamışlardır. Yenilik (innovation) yeni ürün, hizmet ve teknoloji geliştirme olarak tanımlanırken; risk alma (risk taking) kaybetme ihtimaline karşılık eylemde bulunmak olarak ifade edilmektedir. Proaktif davranma (proactiveness) ise ilk girişimi başlatma olarak tanımlanmaktadır (Knight, 1997; Antoncic ve Hisrich, 2001; Morris ve Kuratko, 2002).

İç girişimciliği önemli kılan önemli bir husus örgütün iç çevresindeki çalışanların iş tatminlerine ve özyeterliliklerine etkisidir. Özyeterlilik iç girişimciliği etkileyen bireysel faktör iken, iş tatmini örgütsel bir faktördür (Meydan, 2011). İş tatmini çalışanların iç girişimci davranışlarını etkilemektedir (Şeşen, 2010). İş tatmininin iç girişimcilik üzerindeki etkisinde yöneticilerin yönetim tarzlarının da doğrudan ya da dolaylı etkisi olduğunu gösteren araştırmalar görülmektedir (Heinonen ve Korvela, 2005; Holt vd., 2007; Wood vd., 2008). Buna karşılık iç girişimci davranışların örgütsel faktörlerle karşılaştırıldığında bireysel faktörlerden (özellikle özyeterlilik) daha fazla etkilendiğini gösteren araştırmalar da (Meydan, 2011) bulunmaktadir.

İç girişimciliği önemli kılan bir diğger husus da; örgütlerde çalışan devir hızının düşük, iş tatmininin ve verimliliğin yüksek olmasıdır. Doğal olarak böyle bir performansın sağlanabilmesi örgütlerin iç ve dış çevrelerine uyum yeteneklerine bağlıdır. Çalışanlar örgütün iç çevrelerini oluştururken, inovasyon firsatlarını değerlendirebilecekleri yer örgütlerin dış çevreleridir. Dış çevrelerindeki firsatlarla birlikte yüksek düzeyde belirsizlik ve karmaşıklık; risk alabilmek için daha fazla uyum kabiliyeti gerektirmektedir.

Dışsal uyum ve örgüt içi bütünleşmeyi sağlamada kuşkusuz örgüt liderlerinin çok önemli rolü ve etkisi bulunmaktadır. Bu bağlamda örgüt liderleri için belki de en önemli hususlardan biri liderin yönetim tarzıdır. Yönetim tarzları Kurt Lewin tarafından demokratik-katılımcı yönetim tarzı, otokratik yönetim tarzı ve tam serbesti tanıyan (laissez-faire) yönetim tarzı olarak sınıflandırılmaktadır (akt. Özturan, 2018). Araştırmaya konu olan iç girişimciliği teşvik edeceği ve pozitif etkileyebileceği düşünülen yönetim tarzı demokratik-katılımcı yönetim tarzıdır.

Liderlerin çalışanlara ilham verme, bireysel ilgi gösterme, entellektüel olarak teşvik etme şeklinde iç girişimciliğe dönüşüm sağlamak açısından demokratik-katılımcı yönetim tarzı önem kazanmaktadır. Entellektüel teşvik, liderlerin yenilikçi çözüm aramak için sağladığı destek olarak tanımlanmaktadır (Mengüç ve Auh, 2008: 35) ve iç girişimcilik için önemlidir. Özellikle girişimciliğin yenilik boyutunun en önemli unsur olduğu düşünüldüğünde (Karcığlu ve Kaygın, 2013) iç girişimciliği sağlamak için liderlerin demokratik-katılımcı yönetim tarzının önemi daha iyi anlaşılmaktadır.

Günümüz iş dünyasında yenilikçi yöneticiler demokratik ve ilham verici bir yönetim tarzı ile daha başarılı olabilmekte; dolayısıyla demokratik-katılımcı yönetim tarzı (democraticparticipative management style) izlemeyi tercih etmektedirler (Vasilev ve Todorova, 2016).

Demokratik-katılımcı yönetim tarzı ile çalışanlardan gelebilecek değerli bilgi, öneri ve fikirler sağlanmaktadır (Özturan, 2018). Dolayısıyla iç girişimciliğe esas olan yeni fikirler teşvik edilmektedir. Böylelikle demokratik-katılımcı yönetim tarzının yaygın olduğu kurumlarda, astları kontrol etme ihtiyacı önemini yitirmektedir (Vasilev ve Todorova, 2016). 
Demokratik yönetim tarzı ilişkilerde güven esaslı ve çalışanların karar alma süreçlerine etkin olarak katıldığı yaklaşımdır (Qureshi, 2017).

Literatür taraması çerçevesinde teorik olarak açıklanan demokratik-katılımcı yönetim tarzının iç girişimcilik eğilimine etkisi araştırmanın temel hipotezini oluşturmaktadır. Çalışmanın bundan sonraki kısmında araştırmanın yöntemi, analiz ve bulgular ele alınmaktadır.

\section{Araştırmanın Modeli ve Yöntemi}

Araştırmanın örneklemini İstanbul ilinde havacılık sektöründeki çalışanlardan oluşan 136 katılımcı oluşturmaktadır. Araştırmada en uygun örneklem elde edilebildiği için tesadüfi örnekleme gerçekleştirilmiştir (Tuğsal, 2018). Veriler SPSS 20.0 istatistik paket yazılımı aracılığıyla dönüştürülerek regresyon analizi yapılmıştır. Araştırmanın modeli Şekil 1'de sunulmaktadir.

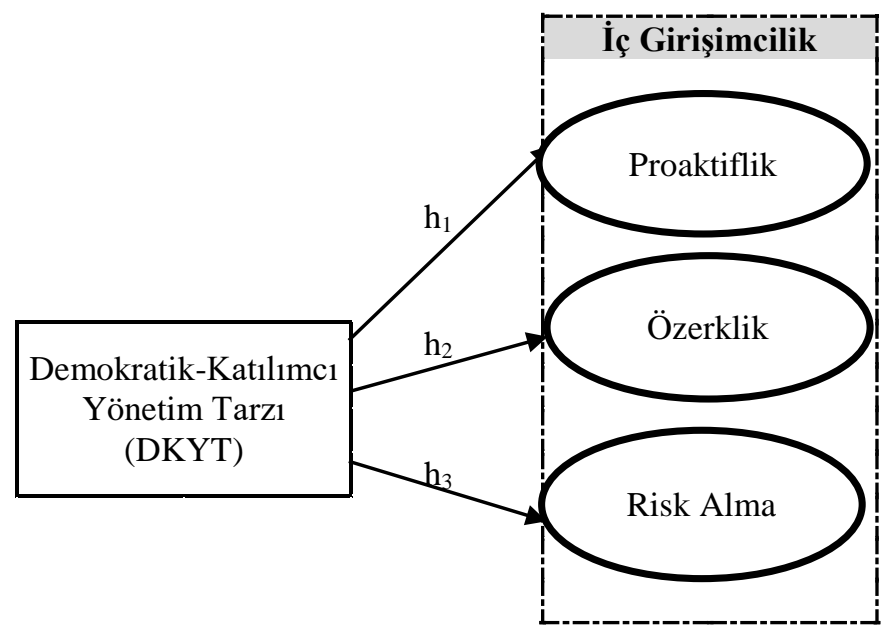

Şekil 1: Araştırmanın Modeli

Araştırmaya katılan çalışanlara ilişkin frekans ve yüzde dağılımları Tablo 1'de belirtilmektedir.

Tablo 1: Frekans ve Yüzde Dağılımı

\begin{tabular}{|c|c|c|c|}
\hline Değișken & Düzey & $\mathbf{N}$ & $\%$ \\
\hline \multirow{2}{*}{ Cinsiyet } & Kadın & 50 & 36,76 \\
\hline & Erkek & 86 & 63,24 \\
\hline \multirow{4}{*}{ Yaş } & $18-29$ & 85 & 62,50 \\
\hline & 30-39 & 29 & 21,32 \\
\hline & $40-49$ & 19 & 13,97 \\
\hline & 50 ve üzeri & 3 & 2,21 \\
\hline \multirow{2}{*}{ Medeni Durum } & Bekâr & 91 & 66,91 \\
\hline & Evli & 45 & 33,09 \\
\hline \multirow{4}{*}{ Eğitim Düzeyi } & Lise & 4 & 2,94 \\
\hline & Yüksekokul & 15 & 11,03 \\
\hline & Lisans & 65 & 47,79 \\
\hline & Lisansüstü & 52 & 38,24 \\
\hline
\end{tabular}




\begin{tabular}{|c|c|c|c|}
\hline & Diğer & 0 & 0 \\
\hline \multirow{4}{*}{ Kidem } & $1-6$ y1l & 76 & 55,88 \\
\hline & 7-10 y1l & 22 & 16,18 \\
\hline & $11-15$ yll & 14 & 10,29 \\
\hline & 16 yıl ve üzeri & 24 & 17,65 \\
\hline \multirow{5}{*}{ Gelir } & $0-2.000 \mathrm{TL}$ & 39 & 28,68 \\
\hline & 2.001-3.500TL & 34 & 25 \\
\hline & 3.501-6.000TL & 42 & 30,88 \\
\hline & $6.001-10.000 \mathrm{TL}$ & 16 & 11,76 \\
\hline & 10.001TL ve üzeri & 5 & 3,68 \\
\hline
\end{tabular}

Araştırmaya 50 kadın ve 86 erkek çalışan katılmıştır. Ankete katılan çalışanlardan 85 kişi (\%62,50) 18-19 yaş grubunda, 29 kişi $(\% 21,32)$ 30-39 yaş grubunda, 19 kişi $(\% 13,97)$ 40-49 yaş grubunda ve 3 kişi $(\% 2,21) 50$ yaş ver üzerindedir. Çalışanların 91'i $(\% 66,91)$ bekâr, 45’i ise $(\% 33,09)$ evlidir. Eğitim düzeylerine bakıldığında 4 kişinin $(\% 2,94)$ lise mezunu, 15 kişinin $(\% 11,03)$ yüksekokul, 65 kişinin $(\% 47,79)$ lisans mezunu ve 52 kişinin $(\% 38,24)$ lisansüstü eğitim aldığı görülmektedir. Araştırmaya katılan çalışanların \%55,88'i yani 76 kişinin kıdemi 1-6 yıl arasındayken, 22 kişinin yani katılımcıların \%16,18'inin kıdemi 7-10 yıl arasında, 14 kişinin $(\% 10,29)$ kıdemi 11-15 yıl arasında ve 24 kişinin $(\% 17,65)$ kıdemi 16 yıl ve üzerindedir. Katılımcıların gelir düzeyine bakıldığında 39 kişinin geliri $(\% 28,68)$ 0-2.000TL arasındayken, 34 kişinin geliri (\%25) 2.001-3.500TL arasında, 42 kişinin geliri $(\% 30,88)$ 3.501-6.000TL arasında, 16 kişinin $(\% 11,76)$ geliri $6.001-10.000 \mathrm{TL}$ arasında ve 5 kişinin geliri $(\% 3,68)$ 10.001TL ve üzerindedir.

Araştırmada, katılımcıların iç girişimcilik eğilimleri ve demokratik-katılımcı yönetim tarzı algılarını ölçmek üzere Kurt ve Terzi’nin (2005) Türkçe geçerlilik ve güvenilirlik çalışmalarını gerçekleştirdiği yönetim tarzı ölçeğindeki demokratik-katılımcı yönetim tarzı alt ölçeği ile Naktiyok (2004) tarafından hazırlanan ve Durmaz (2011) tarafından geliştirilen 21 ifadeden ve 4 boyuttan oluşan iç girişimcilik ölçeği kullanılmıştır.

Öncelikle araştırmada kullanılan iki ölçeğin güvenilirlik analizleri yapılmıştır.

\subsection{Güvenilirlik ve Geçerlilik Analizleri}

Veri setinde kayıp veri olmadığı için örneklemdeki 136 verinin tamamı analizde kullanılmıştır.

Tablo 2: İç Girişimcilik Ölçeği’nin Güvenilirlik İstatistikleri

\begin{tabular}{|c|c|c|}
\hline Cronbach's Alpha & Standart Maddelere Dayalı Cronbach's Alpha & Madde Sayısı \\
\hline .915 & .922 & 21 \\
\hline
\end{tabular}

Cronbach's Alpha katsayısı .61 ile .80 arasında ise ölçek güvenilirliği kabul edilebilir düzeydedir (İslamoğlu ve Alnıaçık, 2014: 283). İç Girişimcilik Ölçeği’nin Cronbach's Alpha değeri .915 olarak saptanmıştır ve ölçeğin güvenilirliğinin yüksek düzeyde olduğu görülmektedir. 
Tablo 3: İç Girişimcilik Ölçeği’nin Ölçek İstatistikleri

\begin{tabular}{|c|c|c|c|}
\hline Ortalama & Varyans & Standart Sapma & Madde Sayı1 \\
\hline 142,325 & 669,354 & 25,8719 & 21 \\
\hline
\end{tabular}

İç Girişimcilik Ölçeği'nin istatistik değerlerinde ortalama 142.325, varyans 669.354, standart sapma 25.8719 ve ölçeğin madde sayısı 21 'dir.

Tablo 4: Demokratik-Katılımcı Yönetim Tarzı Ölçeği'nin Güvenilirlik İstatistikleri

\begin{tabular}{|c|c|c|}
\hline Cronbach's Alpha & Standart Maddelere Dayalı Cronbach's Alpha & Madde Sayısı \\
\hline, 942 &, 943 & 9 \\
\hline
\end{tabular}

Demokratik-Katılımcı Yönetim Tarzı Ölçeği’nin güvenilirlik analizi sonucunda Cronbach's Alpha değeri .942 olarak hesaplanmıştır. Ölçeğin güvenilirliğinin yüksek düzeyde olduğunu göstermektedir.

Tablo 5: Demokratik-Katılımcı Yönetim Tarzı Ölçeği’nin Ölçek İstatistikleri

\begin{tabular}{|c|c|c|c|}
\hline Ortalama & Varyans & Standart Sapma & Madde Sayı1s1 \\
\hline 30,288 & 92,224 & 9,6033 & 9 \\
\hline
\end{tabular}

9 maddeden oluşan Demokratik-Katılımcı Yönetim Tarzı Ölçeği’nin ölçek istatistik değerlerinde ortalama 30.288, varyans 92.224, standart sapma 9.6033 olarak hesaplanmıştır.

Doğrulayıcı faktör analizinde tek faktörle açıklama yapılamayan ölçeklerde açıklayıcı faktör analizi yapılmıştır. Faktör yapısı oluşturulurken faktör analizinde varimax dikey döndürme sonucunda özdeğeri 1 ve üzerinde olan faktörler modelin varyansını/değişebilirliğini açıklamaktadır (İslamoğlu ve Alnıaçık, 2014: 408). Eigen değeri 1'in altında olan faktörler dahil edilmemektedir.

Tablo 6: İç Girişimcilik Ölçeği’nin İstatistik Sonuç Değerleri

\begin{tabular}{|l|c|c|c|}
\hline İstatistik Sonuç Değerleri & Faktör1 & Faktör 2 & Faktör 3 \\
\hline Özdeğerler & 7,686 & 2,527 & 1,370 \\
\hline Açıklanan Kümülatif Varyans (\%) & 36,602 & 48,635 & 55,160 \\
\hline Kaiser-Meyer-Olkin Örneklem Yeterliliği & & & .877 \\
Bartlett Küresellik Testi Ki Kare Değeri & & 1298,110 \\
p & & & .000 \\
Ölçek Cronbach's Alfa Değeri & & .915 \\
\hline
\end{tabular}

Anketteki ifadeler 1-Tamamen Katılmıyorum, 5- Tamamen Kat1lyorum aralıkları arasında değerlendirilmiştir. Kaiser-Meyer-Olkin örneklem yeterliliğinin .877 olduğu hesaplanmıştır. Modelin geçerliliğini test eden Bartlett küresellik testinin Ki Kare sonucu ise 1298,110 'dur ve model $\mathrm{p}<.001$ düzeyinde anlamlıdır.

Açıklayıcı faktör analizi sonucunda bu araştırmada ölçek 3 faktörle açıklanmaktadır. Faktör yükleri Alamur'un (2016) çalışmasındakine benzer bir dağılım göstermiştir. Birinci faktör proaktiflik; ikinci faktör risk alma; üçüncü faktör özerklik olarak ifade edilmektedir. 
Modeldeki birinci faktör olan proaktiflik, toplam varyansın \%36.602'sini; ikinci faktör olan risk alma \%12,032'sini ve üçüncü faktör olan özerklik \%6,525'ini açılamaktadır. Toplamda 3 faktör ile açıklanan ölçeğin kümülatif varyansı \%52.996 olmaktadır; bu yüksek bir orandır. İlginç olan bulgu Türk toplum yapısında yenilikçilik faktörünün etkili olması beklenirken; yapılan açıklayıcı faktör analizi sonucunda bunun desteklenmemesidir.

Açıklayıcı faktör analizindeki ilk faktör olan proaktiflik; çevredeki değişimi yakalamak amacıyla firsatları kovalama ve inisiyatif kullanma olarak tanımlanmaktadır. İkinci faktör olarak açıklanan özerklik; örgüt üyelerinin kendi başlarına karar alma, yeni eylem oluşturabilme gibi bağımsız olmaları olarak tanımlanmaktadır. Açıklayıcı faktör analizindeki üçüncü faktör olan risk alma; firsatları muhtemel tehditlerinin önünde görebilmek olarak tanımlanmaktadır (Alamur, 2016: 105).

Tablo 7: Demokratik-Katılımcı Yönetim Tarzı Ölçeği’nin İstatistik Sonuç Değerleri

\begin{tabular}{|l|c|}
\hline İstatistik Sonuç Değerleri & Faktör1 \\
\hline Özdeğerler & 6,226 \\
\hline Açıllanan Kümülatif Varyans (\%) & 69,173 \\
\hline Kaiser-Meyer-Olkin Örneklem Yeterliliği & .937 \\
Bartlett Küresellik Testi Ki Kare Değeri & 882,916 \\
p & .000 \\
Ölçek Cronbach's Alfa Değeri & .942 \\
\hline
\end{tabular}

Tablo 7'de görüldüğü üzere faktör analizi sonucunda demokratik-katılımcı yönetim tarzı ölçeği tek faktör ile açıklanmaktadır ve istatistik sonuç değerlerinden Kaiser-Meyer-Olkin örneklem yeterliliği değerinin .937 olduğu hesaplanmıştır. Bartlett küresellik testinin sonucu 882,916 'dır ve model $\mathrm{p}<0.001$ düzeyinde anlamlıdır. Demokratik-katılımcı yönetim tarzı boyutu \%69,173 varyans ile açıklanmaktadır.

\subsection{Analiz ve Bulgular}

Anket yoluyla araştırma için toplanan ölçümler, SPSS 20.0 yazılımıyla regresyon analizi ile değerlendirilmiştir. İlk hipotez ile; demokratik-katılımcı yönetim tarzının iç girişimciliğin proaktiflik boyutu üzerindeki etkisi analiz edilmektedir.

h1: Demokratik-katılımcı yönetim tarzının iç girişimciliğin proaktiflik boyutu üzerinde etkisi vardır.

Demokratik-katılımcı yönetim tarzının proaktiflik üzerindeki etkilerin model özeti tablosu, Tablo 8'de görülmektedir. Modelde Durbin-Watson değeri 2.217 olarak hesaplanmaktadır. Durbin-Watson değerinin 2'ye yakın olması modelde sorun olmadığını göstermektedir (Tuğsal, 2018).

Tablo 8: Demokratik-Katılımcı Yönetim Tarzı’nın Proaktiflik Üzerindeki Etkilerin Model Özeti Tablosu

\begin{tabular}{|c|c|c|c|c|c|c|c|}
\hline \multirow{2}{*}{ Aşama } & \multirow{2}{*}{$\mathrm{R}$} & \multirow{2}{*}{$\mathrm{R}^{2}$} & \multirow{2}{*}{$\begin{array}{c}\text { Düzeltilmiş } \\
\mathrm{R}^{2}\end{array}$} & \multicolumn{3}{|c|}{ Değişim İstatistikleri } & \multirow{2}{*}{$\begin{array}{c}\text { Durbin- } \\
\text { Watson } \\
\text { Değeri }\end{array}$} \\
\hline 1 & .758 & .575 & .571 & .575 & 151,467 & .000 & 2.217 \\
\hline
\end{tabular}


Analize tahmin değişkenleri olarak; sabit (Proaktiflik) ve bağımsız değişken dâhil edilmiştir. Modeli birinci aşama \%57.5 varyans ile açıklamaktadır $(\mathrm{p}<.001)$.

Tablo 9: Demokratik-Katılımcı Yönetim Tarzı'nın Proaktiflik Üzerindeki Etkilerin ANOVA İstatistik Değerleri

\begin{tabular}{|c|c|c|c|c|}
\hline Aşama & Kareler Toplamı & Ortalamaların Karesi & F & p \\
\hline 1 & 64.654 & 64.654 & 151.467 & .000 \\
\hline
\end{tabular}

Modelin, Tablo 9'da yer alan ANOVA istatistik değerlerinde, F değerinin istatistiksel olarak $\mathrm{p}<.001$ düzeyinde anlamlı olduğu görülmektedir. İlk aşamada tahmin gücünün anlamlı olduğu görülmektedir $\left(\mathrm{F}_{136-1}=151.467\right)$.

Tablo 10: Demokratik-Katılımcı Yönetim Tarzı'nın Proaktiflik Üzerindeki Etkilerin Katsayılar Tablosu

\begin{tabular}{|l|l|c|c|c|c|c|}
\hline \multirow{2}{*}{ Aşama } & \multirow{2}{*}{ Bağımsız Değişkenler } & \multicolumn{2}{|c|}{$\begin{array}{c}\text { Standartlaştırılmayan } \\
\text { Katsayılar }\end{array}$} & $\begin{array}{c}\text { Standartlaştırılmış } \\
\text { Katsayılar }\end{array}$ & $\mathrm{t}$ & $\mathrm{p}$ \\
\cline { 3 - 7 } & Sabit (Proaktiflik) & .037 & .061 & Beta & & .611 \\
\cline { 2 - 7 } & DemokratikKatilimci & .764 & .062 & .758 & 12.307 & .000 \\
\hline
\end{tabular}

Bağımlı Değişken: Proaktiflik

İstatistiksel hesaplamalar doğrultusunda kabul edilen modelin regresyon denklemi şu şekilde ifade edilmektedir:

$$
\text { Proaktiflik }=.037+[(.764 x \text { Demokratik-Katılımc1 Yönetim Tarzı) }]
$$

Bulgular değerlendirildiğinde demokratik-katılımcı yönetim tarzının iç girişimciliğin proaktiflik boyutu üzerinde istatistiksel olarak anlamlı ve pozitif yönlü etkisi $(p<.001)$ olduğu tespit edilmiştir. Hipotez kabul edilmektedir. Dolayısıyla; demokratik-katılımcı yönetim tarzı 1 birim arttığında, iç girişimciliğin proaktiflik boyutu .764 birim artmaktadır.

Araştırmanın ikinci hipotezi ile demokratik-katılımcı yönetim tarzının iç girişimciliğin özerklik boyutu üzerindeki etkisi analiz edilmektedir.

h2: Demokratik-katılımcı yönetim tarzının iç girişimciliğin özerklik boyutu üzerinde etkisi vardır.

Demokratik-katılımcı yönetim tarzının özerklik üzerindeki etkilerin model özeti tablosu, Tablo 11'de görülmektedir. Modelde Durbin-Watson değeri 1.868 olarak hesaplanmaktadır. Durbin-Watson değerinin 2'ye yakın olması modelde sorun olmadığını göstermektedir (Tuğsal, 2018).

Tablo 11: Demokratik-Katılımcı Yönetim Tarzı'nın Özerklik Üzerindeki Etkilerin Model Özeti Tablosu

\begin{tabular}{|c|c|c|c|c|c|c|c|}
\hline \multirow[b]{2}{*}{ Aşama } & \multirow[b]{2}{*}{$\mathrm{R}$} & \multirow{2}{*}{$\mathrm{R}^{2}$} & \multirow{2}{*}{$\begin{array}{c}\text { Düzeltilmiş } \\
\mathrm{R}^{2}\end{array}$} & \multicolumn{3}{|c|}{ Değişim İstatistikleri } & \multirow{2}{*}{$\begin{array}{l}\text { Durbin- } \\
\text { Watson } \\
\text { Değeri }\end{array}$} \\
\hline & & & & $\mathrm{R}^{2}$ Değişimi & F Değişimi & $\mathrm{p}$ & \\
\hline 1 & .083 & .010 & .001 & .010 & .779 & .379 & 1.868 \\
\hline
\end{tabular}


Analize tahmin değişkenleri olarak; sabit (Özerklik) ve bağımsız değişken dâhil edilmiştir. Modeli birinci aşama \%1 varyans ile açıklamakta görünse de istatistiksel olarak anlamlı değildir ( $\mathrm{p}>.05)$.

Tablo 12: Demokratik-Katılımcı Yönetim Tarzı'nın Özerklik Üzerindeki Etkilerin ANOVA İstatistik Değerleri

\begin{tabular}{|c|c|c|c|c|}
\hline Aşama & Kareler Toplamı & Ortalamaların Karesi & F & p \\
\hline 1 & .811 & .811 & .779 & .379 \\
\hline
\end{tabular}

Modelin ANOVA tablosunda $\mathrm{F}$ değerinin istatistiksel olarak $\mathrm{p}<.001$ düzeyinde anlamlı olduğu görülmektedir. İlk aşamada tahmin gücünün anlamlı olduğu görülmektedir $\left(\mathrm{F}_{136-}\right.$ $1=.779)$.

Tablo 13: Demokratik-Katılımcı Yönetim Tarzı'nın Özerklik Üzerindeki Etkilerin Katsayılar Tablosu

\begin{tabular}{|l|l|c|c|c|c|c|}
\hline \multirow{2}{*}{ Aşama } & \multirow{2}{*}{ Bağımsız Değişkenler } & \multicolumn{2}{|c|}{$\begin{array}{c}\text { Standartlaştırılmayan } \\
\text { Katsayılar }\end{array}$} & $\begin{array}{c}\text { Standartlaştırılmış } \\
\text { Katsayılar }\end{array}$ & $\mathrm{t}$ & $\mathrm{p}$ \\
\cline { 3 - 8 } & B & St. Hata & Beta & & \\
\hline \multirow{2}{*}{ Sabit (Özerklik) } & .024 & .096 & & .252 & .801 \\
\cline { 2 - 7 } & Demokratik Katılımc1 & .086 & .097 & .083 & .882 & .379 \\
\hline
\end{tabular}

Bağımlı Değiş̧en: Özerklik

Bulgular değerlendirildiğinde demokratik-katılımcı yönetim tarzının iç girişimciliğin özerklik boyutu üzerinde istatistiksel olarak anlamlı etkisi olmadığı (p>.05) tespit edilmiştir. Hipotez reddedilmektedir.

Araştırmanın üçüncü hipotezi ile demokratik-katılımcı yönetim tarzının iç girişimciliğin risk alma boyutu üzerindeki etkisi analiz edilmektedir.

$\boldsymbol{h}_{3}$ : Demokratik-katılımcı yönetim tarzının iç girişimciliğin risk alma boyutu üzerinde etkisi vardır.

Demokratik-katılımcı yönetim tarzının risk alma üzerindeki etkilerin model özeti tablosu, Tablo 14'te görülmektedir. Modelde Durbin-Watson değeri 2.266 olarak hesaplanmaktadır. Durbin-Watson değerinin 2'ye yakın olması modelde sorun olmadığını göstermektedir (Tuğsal, 2018).

Tablo 14: Demokratik-Katılımcı Yönetim Tarzı'nın Risk Alma Üzerindeki Etkilerin Model Özeti Tablosu

\begin{tabular}{|c|c|c|c|c|c|c|c|}
\hline \multirow[b]{2}{*}{ Aşama } & \multirow{2}{*}{$\mathrm{R}$} & \multirow{2}{*}{$\mathrm{R}^{2}$} & \multirow{2}{*}{$\begin{array}{c}\text { Düzeltilmiş } \\
\mathrm{R}^{2}\end{array}$} & \multicolumn{3}{|c|}{ Değişim İstatistikleri } & \multirow{2}{*}{$\begin{array}{l}\text { Durbin- } \\
\text { Watson } \\
\text { Değeri }\end{array}$} \\
\hline & & & & $\mathrm{R}^{2}$ Değişimi & F Değişimi & $\mathrm{p}$ & \\
\hline 1 & .158 & .025 & .016 & .025 & 2.851 & .094 & 2.266 \\
\hline
\end{tabular}

Analize tahmin değişkenleri olarak; sabit (Risk Alma) ve bağımsız değişken dâhil edilmiştir. Modeli birinci aşama \%2,5 varyans ile açıklamakta görünse de istatistiksel olarak anlamlı değildir ( $\mathrm{p}>.05)$. 
Tablo 15: Demokratik-Katılımcı Yönetim Tarzı'nın Risk Alma Üzerindeki Etkilerin ANOVA İstatistik Değerleri

\begin{tabular}{|c|c|c|c|c|}
\hline Aşama & Kareler Toplamı & Ortalamaların Karesi & F & p \\
\hline 1 & 2.872 & 2.872 & 2.851 & .094 \\
\hline
\end{tabular}

Modelin ANOVA tablosunda F değerinin istatistiksel olarak $\mathrm{p}<.001$ düzeyinde anlamlı olduğu görülmektedir. İlk aşamada tahmin gücünün anlamlı olduğu görülmektedir ( $\mathrm{F}_{136-}$ $\left.{ }_{1}=2.851\right)$.

Tablo 16: Demokratik-Katılımcı Yönetim Tarzı'nın Risk Alma Üzerindeki Etkilerin Katsayılar Tablosu

\begin{tabular}{|l|l|c|c|c|c|c|}
\hline \multirow{2}{*}{ Aşama } & \multirow{2}{*}{ Bağımsız Değişkenler } & \multicolumn{2}{|c|}{$\begin{array}{c}\text { Standartlaştırılmayan } \\
\text { Katsayılar }\end{array}$} & $\begin{array}{c}\text { Standartlaştırılmış } \\
\text { Katsayılar }\end{array}$ & $\mathrm{t}$ & $\mathrm{p}$ \\
\cline { 3 - 7 } & $\mathrm{B}$ & St. Hata & Beta & & \\
\hline \multirow{2}{*}{ Sabit (Risk Alma) } & .008 & .094 & & .085 & .933 \\
\cline { 2 - 7 } & DemokratikKatilimci & .161 & .095 & .158 & 1.688 & .094 \\
\hline
\end{tabular}

Bağımlı Değişken: Risk Alma

Bulgular değerlendirildiğinde demokratik-katılımcı yönetim tarzının iç girişimciliğin özerklik boyutu üzerinde istatistiksel olarak anlamlı etkisi olmadığ 1 ( $p>.05)$ tespit edilmiştir. Hipotez reddedilmektedir.

\section{Sonuç ve Tartışma}

Yöneticilerin demokratik-katılımcı yönetim tarzlarının çalışanların iç girişimcilik algılarına yönelik yapılan araştırmada iç girişimciliğin proaktiflik boyutuyla istatistiksel olarak anlamlı ve pozitif bir ilişki saptanmıştır. Buna karşılık iç girişimciliğin diğer iki boyutu olan risk alma ve özerklik boyutları üzerinde demokratik-katılımcı yönetim tarzının istatistiksel olarak anlamlı bir etkisi olmadığı görülmektedir.

Araştırma sonuçlarını çalışmanın yapıldığı havacılık sektörü bağlamında değerlendirmek gerekirse; çalışanların kendi başlarına karar alma, yeni eylem oluşturabilme, bağımsız hareket edebilme özelliklerini kapsayan özerkliğin etkili olmaması, Türk havacılık sektöründe ast-üst ilişkisinin, hiyerarşi ve komuta kademelerinin etkili olması ile açıklanabilir. Havacılık sektöründe en önemli unsurların petrol fiyatları, turist sayısı, bilet fiyatları, ülke güvenliği, acenta tur satışları gibi stratejik öneme sahip hususlar olduğu dikkate alındığında çalışanların özerkliklerinin etkisi olmaması anlaşılabilir. Bu hususların çalışanların özerklik eğilimlerinde olduğu gibi risk alma eğilimlerinin de etkisiz olmasına sebep olabileceği düşünülmektedir. Gelir elde etmesini sağlayan turizm sektörü ile ve diğer taraftan maliyetlerinin büyük bir kısmını oluşturan petrol-akaryakıt sektörüyle karşılıklı bağımlılık ilişkisi de bulunan havacılık sektöründe firsatlar ve tehditlerin üst yönetim tarafından değerlendirilmesi daha uygun olabilir. Dolayısıyla çalışanların risk alma eğilimlerinin düşük olması bu durumla açıklanabilir.

Özerklik ve risk alma eğilimlerinin etkisi olmamakla birlikte çalışanların iç girişimciliklerinde firsatları kovalama ve inisiyatif kullanma olarak tanımlan proaktiflik eğilimleri çok yüksek düzeydedir. Ulusal ve uluslar arası çapta rekabetin fazla olduğu havacılık sektöründe; satış gelirlerini arttırmak ve maliyetleri düşürmek, müşteri sayısını ve iç ve dış destinasyon sayısını arttırmak üzere tüm fırsatların değerlendirilmesi çok büyük önem teşkil 
etmektedir. Bu bağlamda, rekabet üstünlüğü elde etmek için şirketlerin iç girişimciler olarak çalışanlarının proaktiflik düzeylerini yükseltmeye yönelik insan kaynakları politikaları uygulamaları önerilebilir.

Heinonen ve Korvela (2005), Holt vd. (2007), Wood vd.'nin (2008) iç girişimcilik üzerinde yöneticilerin yönetim tarzlarının doğrudan ya da dolaylı etkisi olduğunu vurguladığı üzere; demokratik-katılımcı yönetim tarzının iç girişimcilik üzerindeki etkisinin araştırıldığı bu çalışma alanyazına katkı sağlamayı amaçlamaktadır. Gelecekte yapılacak çalışmalar için araştırmacılar iç girişimciliğin daha düşük düzeyde olabileceği düşünülen kamu sektöründe otokratik yönetim tarzının etkilerini araştırabilirler.

\section{Kaynakça}

Ağca, V. \& Kurt, M. (2007). İç Girişimcilik ve Temel Belirleyicileri: Kavramsal Bir Çerçeve. Erciyes Üniversitesi İ.İ.B.F. Dergisi, Sayı: 29, Temmuz-Aral1k, 83-112.

Alamur, B. (2016). Olgun örgütlerde iç girişimciliğin canlandırılmasında örgütsel zekâ'nın rolü. Yayımlanmamış doktora tezi. Dumlupinar Üniversitesi Sosyal Bilimler Enstitüsü, Kütahya.

Antoncic B., Hisrich R.D. (2001). Intrapreneurship: construct refinement and cross-cultural validation. Journal of Business Venturing, Vol.16, No.5, pp.495-527.

Antoncic, B. \& Hisrich, R.D. (2003). Clarifying the Intrapreneurship Concept. Journal of Small Business and Enterprise Development, 10 (1), 7-24.

Covin, J.G. ve Slevin, D.P. (1986). The Development and Testing of An Organizational-level Entrepreneurship Scale. İçinde Ronstadt, R (Editör), Frontiers of Entrepreneurship Research (628-639). Wellesley: Babson College.

Covin, J.G. ve Slevin, D.P. (1991). A Conceptual Model of Entrepreneurship as Firm Behavior, Entrepreneurship Theory \& Practice, 16(1): 7-25.Culhane, 2003.

Durmaz, I., (2011). Psikolojik Güçlendirme Algısının İç Girişimcilik Üzerine Etkisi. Doktora Tezi, Gazi Üniversitesi Sosyal Bilimler Enstitüsü İşletme Anabilim Dalı, Ankara.

Esposito, J. C. (2006). You're the Boss. Career World, 34 (6), 6-10.

Guth, W. ve Ginsberg, A. (1990). Guest Editors’ Introduction: Corporate Entrepreneurship, Strategic Management Journal, 11: 297-308.

Gürel, E. B. B. (2012). İç Girişimcilik: Bir Literatür Taraması. Gümüşhane Üniversitesi, Sosyal Bilimler Elektronik Dergisi, Sayı 6, 56-75.

Heinonen, J., ve Korvela, K. (2005). How About Measuring Intrapreneurship?, http://labsel.netco.it/Modules/ContentManagment/Uploaded/CMItemAttachments/How \%20about\%20measuring\%20intrapreneurship.pdf, (Erisim tarihi: 07.05.2018), 1-18.

Hisrich, R.D., Peters, M.P., Shepherd, D.A. (2005). Entrepreneurship. (6th edition) New York.

Holt, D. T., Rutherford, M. W. ve Clohessy, G. R. (2007). Corporate Entrepreneurship: An Empirical Look At Individual Characteristics, Context and Process. Journal of Leadership and Organizational Studies, 13 (4), 40-54.

İslamoğlu, A. H., Alnıaçı, Ü. (2014). Sosyal Bilimlerde Araştırma Yöntemleri. Beta Yayınları, İstanbul. 
Jones G. R., Butler J. E. (1992). Managing Internal Corporate Entrepreneurship: An Agency Theory Perspective, Journal of Management, 18,4:733.

Karcıoğlu, F., Kaygın, E. (2013). Girişimcilik sürecinde dönüştürücü liderlik anlayışı: Otomotiv sektöründe bir uygulama. Atatürk Üniversitesi İktisadi ve İdari Bilimler Dergisi, Cilt: 27, Say1: 3, ss.1-20.

Knight, G.A. (1997). Cross-cultural Reliability and Validity of A Scale To Measure Firm Entrepreneurial Orientation, Journal of Business Venturing, 12(3): 213-25.

Kuratko, D. F., Hodgetts, R. M. (2001),Entrepreneurship: A contemporary approach. Mason, $\mathrm{OH}$ : South-Western Thomson Learning.

Kurt, T., Terzi, A.R. (2005). İlköğretim Okulu Müdürlerinin Yöneticilik Davranışlarının Öğretmenlerin Örgütsel Bağlılığına Etkisi. Milli Eğitim Üç Aylık Eğitim ve Sosyal Bilimler Dergisi. Y.33, S. 166.

Menguc, B., Auh, S. (2008) “Conflict, Leadership, And Market Orientation”, Intern. J. of Research In Marketing, 25, ss. 34-45.

Meydan, C. H. (2011). İş Tatmin Ve Öz Yeterliliğin Örgüt İçi Girişimciliğe Etkisi: Kamu Sektöründe Bir Araştırma. Ç.Ü. Sosyal Bilimler Enstitüsü Dergisi, Cilt 20, Sayı 1,25-40.

Miller, D., Friesen, P.H. (1983). Strategy-making and Environment, Strategic Management Journal, 4: 221-235.

Morris, M.H., Kuratko, D.F. (2002). Corporate Entrepreneurship: Entrepreneurial Development Within Organizations. Orlando, Fl: Harcourt College Publishers.

Naktiyok, A. (2004). İç Girişimcilik, Beta Yayınları, İstanbul.

Özturan, M. (2018). Yöneticilerin duygusal zekâ düzeylerinin, yönetim tarzlari ve örgütsel yabancilaşma duygulari üzerindeki etkisinin incelenmesi. Yayınlanmamış Doktora Tezi. İstanbul Ticaret Üniversitesi / Sosyal Bilimler Enstitüsü, İstanbul.

Pinchot, G. III (1985). Intrapreneuring: Why you don't have to leave the corporation to become entrepreneur. New York: Harper and Row.

Qureshi, I. (2017). Role and Size of a Leader in Organizational Behaviors. Journal of HR, Organizational Behaviors \& Entrepreneurship Development, April 2017, Vol. 1, Issue, 01, 13-16.

Rule, E.G., Irwin, D.W. (1988). Fostering Intrapreneurship: The New Competitive Edge, The Journal of Business Strategy, 9 (3), ss. 44-47.

Şeşen, H., (2010). Öncülleri ve Sonuçları ile Örgüt İçi Girisimcilik: Türk Savunma Sanayinde Bir Arastırma, Yayımlanmamıs Doktora Tezi, KHO Savunma Bilimleri Enstitüsü, Ankara.

Sharma, P., Chrisman, J. J. (1999). Toward A Reconciliation of The Definitional Issues in the Field of Corporate Entrepreneurship. Entrepreneurship Theory and Practice, Spring, 1999, pp.11-28.

Tuğsal, T. (2018). İş-Yaşam Dengesi, Sosyal Destek ve Sosyo-Demografik Faktörlerin Tükenmişlik Üzerindeki Etkisi. İstanbul: Cinius Yayınları

Vasilev, A. ve Todorova, T. (2016). Some Transaction Cost Effects of Authoritarian Management. Econstor, e-Makale. https://www.econstor.eu/handle/10419/145297 Erişim Tarihi: 21.05.2018. 
Wood, C. C., Holt, D. T., Reed, T. S., ve Hudgens, B. J. (2008 ). Perceptions of Corporate Entrepreneurship in Air Force Organizations: Antecedents and Outcomes. Journal of Small Business and Entrepreneurship, 21(1), 117-132.

Zahra S.A. (1991). Predictors and financial outcomes of corporate entrepreneurship: An exploratory study. Journal of Business Venturing, Vol.6, No.4, pp.259-285.

Zahra, S.A. (1993). Environment, Corporate Entrepreneurship, and Financial Performance: A Taxonomic Approach, Journal of Business Venturing, 8: 319-40.

\section{EXTENDED ABSTRACT}

\section{The Impact of the Democratic-Participative Management Style of Managers on the Intrapreneurship Tendencies of Employees}

The scope of the research is to investigate the impact of democratic-participative management style on the intrapreneurship tendencies of employees. Research survey in May 2018 in the province of Istanbul in Turkey is provided with the participation of 136 people working in the aviation sector. The method for analysis is multiple regression analysis. According to the results of the regression analysis, the democratic-participative management style has a statistically significant, positive and high-level effect on the proactiveness dimension of intrapreneurship $(\mathrm{p}<.001)$. There is no significant effect on autonomy and risk taking dimensions.

With the first hypothesis; the impact of democratic-participative management style on intrapreneurship's proactiveness dimension is analysed. It is determined that the democraticparticipative management style has a statistically significant and positive effect on the intrapreneurship's proactiveness dimension ( $\mathrm{p}<.001$ ). Hypothesis is accepted. Therefore; when the democraticparticipatory management style increases by 1 unit, the proactiveness dimension of intrapreneurship increases by .764 units. According to the second and the third hypotheses of the study it is determined that the democratic-participative management style has no statistically significant effect on intrapreneurship’s autonomy and risk taking dimensions ( $\mathrm{p}>.05$ ). The hypotheses are rejected.

Proactiveness tendencies which are defined as pursuing opportunities and using initiatives in intrapreneurship of employees are very high. In the aviation sector, where national and international competition is high; it is very important to evaluate all opportunities to increase sales revenue and reduce costs, increase the number of customers and increase the number of domestic and foreign destinations. It is better understood that the proactiveness defined as intrapreneurs chasing these opportunities and using initiatives are high.

It would be more appropriate to evaluate the research results in the context of the aviation sector in which the study is conducted. In this context; the fact that autonomy, which includes the ability of employees to make decisions on their own and to act independently is not influential. This can be explained by the influence of subordinate relations and hierarchy in the Turkish aviation sector. It can be better understood that the most important elements in the aviation sector are not the effects of employees' autonomy, given that there are strategic prescribers such as oil prices, number of tourists, ticket prices, country security and agency tour sales. 